\title{
Organizational Commitment and Rewards in Thailand, with Comparison between University Graduates and Others
}

\author{
Keisuke Kokubun ${ }^{1}$ \\ ${ }^{1}$ International Economy and Work Research Institute, Osaka, Japan \\ Correspondence: Keisuke Kokubun, International Economy and Work Research Institute, 3-14 \\ Kitahama-Higashi, Chuo-ku, Osaka, 540-0031, Japan. E-mail: kokubun@iewri.or.jp
}

Received: April 27, 2017

Accepted: May 2, 2017 Online Published: May 31, 2017

doi:10.5539/ass.v13n6p1

URL: https://doi.org/10.5539/ass.v13n6p1

\begin{abstract}
This study investigates the relationship between extrinsic, intrinsic and social rewards, and the organizational commitment of 6,911 employees who work for 13 Japanese companies in Thailand. Hierarchical regression analysis revealed that variables included to measure extrinsic, social and intrinsic rewards were strongly related to organizational commitment. These findings suggest that the antecedents of organizational commitment in the Japanese companies in Thailand are different from those in the other kind of corporations in the West. The comparison between University graduates and others showed that benefit satisfaction and fatigue had stronger and supervisor support and role clarity had weaker influence on organizational commitment in university graduates than in others. Discussions and implications concerning human resource management of Japanese companies in Thailand are offered.
\end{abstract}

Keywords: Thailand; exploratory factor analysis, organizational commitment, Japanese companies; rewards

\section{Introduction}

As one of the most successful countries in the developing world, Thailand has attracted many of the world's largest multinational companies to invest and establish operations in many parts of the country. Among them, Japanese companies continue to benefit from Thailand's growth and remain the leading investors in Thailand, which accounts for 2.9\% of total Japan's foreign direct investment (JDI) in 2015 (Japan External Trade Organization, 2016). In response to the yen's appreciation against the dollar following the 1985 Plaza Accord, JDI in Thailand has shown a remarkable increase. JDI accounted for $62.2 \%$ of the total FDI in 2012 and became Thailand's largest source of foreign capital (Morishita, 2012). The number of Japanese companies located in Thailand in April 2016 is 4,788, which have the largest share 30.4\% of total Japanese companies in ASEAN. Among them, the number of manufacturing companies is 2,456 , sharing $51.3 \%$ of the total Japanese companies in Thailand (Teikoku Data Bank, 2016).

However, in Thailand, where many Japanese companies as well as companies from other countries operate, the labor supply is tight. Unemployment rate decreased from 3.33\% in 1980 to $0.88 \%$ in 2015 (International Monetary Fund, 2016). Besides, the labor force population is expected to start declining after 2018 (Takada, 2015 ) and meet the end of 'population bonus' in 2031 which is caused by the aging of society more than 10 years earlier than most neighboring countries such as Vietnam, Indonesia and Malaysia (Shiino, 2015). Accordingly, companies located in Thailand have to cope with the sellers' labor market which allows a large number of employees resigning from their positions. Annual employee turnover rate in Thailand is $14.0 \%$ in 2011 (Employers Confederation of Thailand, 2012) and complaints heard from Japanese managers of local affiliates in Thailand are 'there are not enough persons who can be in charge of managers and engineers', 'turnover rate is high, especially among young people in their late 20's and early 30's', etc (Hagiwara, 2014). Furthermore, previous survey shows that shortage of talented workers in the field of science in Thailand is more serious than in Singapore and Malaysia (Sugita, 2015).

In line with the problem of labor shortage, it is pointed out that surging personnel costs, triggered by the revision of minimum wage in April 2012, is weakening export competitiveness especially of labor intensive industries (Sugita, 2015). Accordingly, falling into the 'middle income trap' is worried if investments from foreign countries decrease and move to neighboring states in future (Horie, 2016). As Thailand aims to shift its industrial structure from labor-intensive to high-value-added one (Thailand Board of Investment, 2014), it is crucial for 
organizations to pay more attention to the issue of securing human resources, especially of skilled and talented employees, to succeed in the global competition.

In this situation, it is necessary to determine how Japanese companies can reduce their employee turnover rates or attract the best employees in Thailand. So, this study analyzes antecedents of organizational commitment (OC) and difference between university graduates and other workers who are employed by Japanese firms. The reason why the researcher focuses on university graduates is because they are considered to become the key for further development of this country, which faces depopulation and seeks for higher efficiency. Actually, the Thai government has aimed advancement of overall industry raising the rate of enrollment in higher education institutions from 33\% in 1999 to 46\% in 2010 (Recruit Works Institute, 2013).

\section{Literature Review}

\subsection{Organizational Rewards in Thailand}

The achievement of an organization does not only rely on how the organization utilizes its human capitals and competencies but also on how it incites commitment to the organization (Beukhof, Jong, \& Nijhof, 1998). Hence, there is growing evidence to suggest that organizations can enhance the commitment of their workforce through the provision of organizational rewards (Newman, Thanacoody, \& Hui, 2011). The social exchange theory supposes that when an individual is happy with the rewards provided by their organization, they will reciprocate by developing positive attitudes towards their organization such as higher levels of commitment (Haar, \& Spell, 2004). Besides, it was shown that enhancement of OC brings higher productivity and lower turnover rate (Meyer, et al., 2002). In Thai setting, it is revealed that OC has significantly positive influence on turnover intention, self-efficacy and businesses performance (Nurittamont, 2012; Yamazaki \& Petchdee, 2015).

However, despite tremendous research on OC (Meyer et al., 2002), there is little research on OC and its antecedents in non-Western countries and Thailand in particular. Furthermore, it is unclear how different categories of organizational rewards might influence organizational commitment in Japanese companies in developing countries such as Thailand. So, before proceeding to concrete analyses, it will be better to review characteristics of the Thai culture as members of a culture will have similar sets of preferences built into how they view the world (Hofstede, 2001).

The Thai culture is normally described as high collectivism, where it is called for greater emotional dependence of members on their organizations, which in turn assume a broad responsibility for their members (Hofstede, 1980). In line with this assertion, Prpic and Kanjanapanyakom (2004) describe Thai culture as kreng jai (not wishing to impose on others), namjai (showing concern for others) and jaiyen (being kind). In another research, Siengthai and Vadhanasindhu (1991) find that Thai subordinates always follow such Thai cultural norms in the workplace. Therefore, the managers in Thailand are expected to recognize these norms in order to create good relationships with their subordinates. Therefore, Thais may have a real sense of belonging in their organizations, and tend to bond more with managers, feeling that other employees are part of the family (Martaet al., 2013).

However, these assertions contradict with understanding of most Japanese managers who work for local affiliates in Thailand. Despite their high collectivistic culture, it is said that people in Thailand tend to be individualistic at work. According to Tanno (1991), characteristics of Thai employees may be drawn as individualistic, reluctant to be controlled from others, low loyalty, low sense of belonging, willing to become independent, dislike following the rules, etc, making the corporate management difficult in Thailand. He argues the reason why Thai people have become individualistic is because: there is no strict hierarchy in Thai villages and members' independence and autonomy are respected there; nuclear families are typical as the family system in Thailand, as people apart from parents and build independent homes once they get married, being different from extended families in China or immediate families in Japan. Therefore, their individualism is thought to have been molded by these environments in which they were brought up (Tanno, 1991). On the other hand, Wilson (1962) attributed Thai individualism to Hinayana Buddhism and rich natural resources which reduce necessity of people's dependence to others.

In line with the discussions above, it may be reasonable to assume that Thais are sometimes collectivistic and other times individualistic depending on the nature of situations. If this assertion is true, the influential factors for OC would be various as its antecedents are said to depend on whether he/she is collectivistic or individualistic (Boyacigiller \& Adler, 1991). This study aims to gain a deeper understanding into the different effects of extrinsic, social and intrinsic rewards on the development of the OC of employees who work for Japanese companies in Thailand.

Porter and Lawler (1968) defined intrinsic rewards as the satisfaction that a person derives from doing the job 
and extrinsic rewards as tangible benefits obtained as a result of doing the job, such as pay and promotions. On the other hand, according to Mottaz (1985), social rewards refer to those that are derived from interpersonal relationships with colleagues and supervisors. As there are a few researches in this field in Thailand, the researcher here tentatively picks up China as a substitute to consider the relation between OC and rewards in this research because China shares with Thailand some similarities not only on geographical positions, economic stages, etc. but also on human matters such as collectivism, and there are more stocks of researches than in most other Asian countries. Previous work in the West and China are summarized as: (i) intrinsic rewards have a greater impact on OC of employees in the West than extrinsic or social rewards (Eby et al., 1999; Malhotra, Budhwar, \& Prowse, 2007; O'Reilly \& Caldwell, 1980); and (ii) extrinsic and social rewards have a greater impact on OC of Chinese employees than intrinsic rewards (Miao et al., 2013; Newman \& Sheikh, 2012).

As it was found by Hofstede (1980) that culture of a country changes as its economy develops, difference between '(i)' and '(ii)' might be attributed not only to geographical features such as the West and the East but also to economic stages on which each country is placed. Furthermore, Boyacigiller and Adler (1991) argue that the commitment of employees with collectivist values may arise from ties with managers, owners and co-workers, whereas the commitment of employees with an individualist orientation may be due to the job itself or the compensation system. If these assertions are true, the reason of '(i)' might be attributed as follows: as Western countries are overall more developed than others, employees are more individualistic and intrinsic rewards are accordingly more important for OC. On the other hand, for '(ii)', it may be assumed that: as China is less developed than Western countries, employees are less individualistic and social rewards are accordingly more important for OC. The reason why extrinsic rewards are important for OC of employees in China in spite of its collectivistic culture will be that economy of China is still in transition and most employees have to work for resources for subsisting.

Supposing that such relationship between economic level and culture may be applicable worldwide, how can we consider about effective rewards for enhancing OC in Thailand? As employees are citizens of developing country Thailand and considered to share common characteristics with China in this sense, it is reasonable to assume that extrinsic and social rewards are associated with $\mathrm{OC}$ in line with '(ii)'. In addition, Japanese companies may reasonably adapt to Thai collectivism because a company in Japan is considered to be a second family which encourages intensive socialization (Jackson \& Tomioka, 2004) and require managers closely involved with a work group (Whitney, 1994, p.100), even though nowadays Japanese management changes and parts from such family-like style due to economic stagnation and the influence of globalization (Haghirian, 2010). However, as Thai people at the same time have a culture of individualism as described above, it is also considerable that intrinsic rewards are associated with OC in line with '(i)'. In short, intrinsic, extrinsic and social rewards are all assumed to have positive effects to OC in Japanese companies in Thailand. The present study is the first to test whether such assumption is true and should enable us to advise managers who work for companies in Thailand as to what strategies may be utilized to foster high levels of OC amongst their employees.

\subsection{Extrinsic Rewards}

\subsubsection{Benefit Satisfaction}

The provision of benefits should lead the employees to reciprocate through exhibiting higher levels of OC. Empirical work in the West (Mottaz, 1988; Loscocco, 1990; Williamson, Burnett, \& Bartol, 2009) is generally supportive of such assertions, although some work finds contradictory evidence (Malhotra, Budhwar, \& Prowse, 2007). Besides, recent work suggests that Chinese employees typically rank extrinsic benefits highly in comparison with intrinsic factors (Chiu, Luk, \& Tang, 2002; Newman \& Sheikh, 2012).

In Thai setting, it is revealed that pay and benefit are positively associated with OC (Colignon, Usui, Kerbo, \& Slagter, 2007). Likewise, Koonmee, Singhapakdi, Virakul, and Lee (2010) find that cares for extrinsic benefits such as meeting health/safety needs and providing good pay and job security increase employee job satisfaction and OC. Likewise, Yamazaki and Petchdee (2015) find that fair and proper HR policies positively influence OC. This leads us to the following hypothesis:

Hypothesis 1: Benefit satisfaction is positively related to OC.

\subsubsection{Fatigue}

A number of studies demonstrate that exhausted workers exhibit lower levels of OC and then finally, there is a possibility of finding employment elsewhere (Azeem, 2010; Lee \& Ashforth, 1996; Wright \& Cropanzano, 1998). On the basis of the ongoing argument, the researcher feels it is needed to check the relationship of emotional exhaustion and OC in Japanese companies in Thailand. This leads us to the following hypothesis: 
Hypothesis 2: Fatigue is negatively related to OC.

\subsection{Social Rewards}

\subsubsection{Supervisor Support}

Empirical studies have provided evidence that perceptions of supervisory support positively affect employees' motivation and OC (Eisenberger et al., 1986; Mottaz, 1988). Recent work conducted in Chinese organizations (He, Lai, \& Lu, 2011; Miaoet al., 2013; Nazir et al., 2016; Newman \& Sheikh, 2012; Wang, 2008) demonstrates a strong relationship between supervisor support and OC, too. However, recent empirical work on private sector employees in the UK provides limited support for such assertions (Malhorta, Budhwar, \& Prowse, 2007).

In the previous research in Thai setting, a positive relationship between transformational leadership style and OC of employees is found (Amornpipat, McLean, \& Katekaew, 2014; Chongvisal, 2002; Newchantuek, 2002; Nilpan, 2000), showing the importance of leaders' various supports for OC. Likewise, it is revealed that the perception of managerial aloofness is negatively and confiding personal information with one's supervisor is positively related to OC (Colignon, et al., 2007). Another research suggests that reliable, supportive, impartial and trustful supervisors reduce turnover intention, although may not have direct association with OC (Yamazaki \& Petchdee, 2015). This leads us to the following hypothesis:

Hypothesis 3: Supervisor support is positively related to OC.

\subsubsection{Co-worker Support}

As it is an important channel for the dissemination of workplace knowledge and newcomer socialization into the organizational culture (Korczynski, Shire, Frenkel, \& Tam, 2000), the provision of support by co-workers should engender greater feelings of emotional attachment to the organization (Mottaz, 1988). Empirical work typically confirms a positive relationship between co-worker support and OC of Western employees (Chiaburu \& Harrison, 2008; Self, Holt, \& Schaninger, 2005; Steijn \& Leisink, 2006) and Chinese employees (He, Lai, \& Lu, 2011; Miao, et al., 2013; Nazir, et al., 2016), although some recent work on Chinese employees find no evidence of such relationship (Newman \& Sheikh, 2012; Wang, 2008).

According to Hofstede (1980), Thailand is a member of collectivist cultures which are characterized as having high loyalty towards the organization and its goals, seeing themselves as interdependent with others, taking action jointly on a cooperative rather than competitive basis, and as valuing joint efforts and group rewards. Besides, Japanese companies have an organizational setting in which there are close-knit relationships between individuals, which is similar to Thai culture. Previous research of Pornpitakpan (1999) suggests that Thai and Japanese people commonly belong to collectivist cultures which focus on fitting in with others, social harmony, interpersonal sensitivity and conformity. Supporting such assertions, an empirical research in the Thai setting suggests that, by comparative study of Thai employees working in Thai and American airlines, significant relationship between co-worker support and OC was found in the Thai sample whereas such relationship was not statistically significant in the US sample (Limpanitgul et al., 2014). Another research shows that functional interdependence (working closely with others) of employees as well as the number of friends in the organization are associated with OC (Colignon et al., 2007). This leads us to the following hypothesis:

Hypothesis 4: Co-worker support is positively related to OC.

\subsection{Intrinsic Rewards}

\subsubsection{Autonomy}

Autonomy is the degree to which employees are allowed freedom, independence and discretionary powers when performing their job tasks and responsibilities (Sims, Szilagyi, \& Mckemey, 1976). The more autonomy an employee has about what, when and how to do work, the greater he/she would feel a sense of responsibility for the job tasks, feel they are needed in the workplace and engender high levels of OC (Williamson, Burnett, \& Bartol, 2009). Empirical findings generally support such assertions in organizations in the West (Eby, et al., 1999; Malhortaet al., 2007; Steijn \& Leisink, 2006). Besides, recent work conducted in Chinese organizations demonstrates a strong relationship between autonomy and OC (Chen \& Aryee, 2007; Froese \& Xiao, 2012; Miao, et al., 2013; Nazir, et al., 2016; Newman \& Sheikh, 2012). Some research conducted in other Asian countries, such as the work of Gautam, van Dick, \& Wagner (2001) in Nepal, is also supportive.

In line with previous research in other Asian countries, it is reasonable to assume that autonomy is important even in Thailand. Besides, despite their high collectivistic culture, Thai people tend to be individualistic at the work and dislike to be controlled by rules due to the nature of villages they were brought up (Tanno, 1991). Actually, in empirical research in Thai setting, participation in decision making is positively related to OC 
(Colignon et al., 2007). This leads us to the following hypothesis:

Hypothesis 5: Autonomy is positively related to OC.

\subsubsection{Training Provision}

The greater the sense of debt incurred with the training program, the employees become more committed and devoted to the organization (Barrett \& O'Connell, 2001). Specifically, the employees that viewed training as the most relevant to their current jobs were able to attain more positive commitment outcomes and had less of intention to quit (Burke, 1995). Some findings from empirical work on employees in the West are supportive of a link between training provision and OC (Bartlett, 2001; Owens, 2006; Wayne et al., 1997) but some other studies found insignificant relation (Shore \& Barksdate, 1998) or significant but negative relation (Smeenk et al., 2006).

The reasons of such mixed results may partly be because of market imperfection in which a company is not always successful to employ a person whose skill is compatible to what the company needs. In this setting, training will not be fully effective to enlarge an employee's skill and cause his/her reciprocity. Another reason might be that skills obtained through training are sometimes not specific to a company but general and portable to elsewhere. In this setting, a company may not induce an employee's OC fully (Becker, 1993).

In Chinese setting, Newman, Thanacoody, and Hui (2011) found a significant impact of training on OC of employees working for multinational enterprises in China. In Thailand setting, Yamazaki and Petchdee (2015) have shown that providing growth and learning opportunities have a significant and positive relationship with OC. Likewise, another research shows that the relationship between structural empowerment and OC is high (Vichian, 2016). Most previous research in Asian setting is supportive to the association between training and OC, except some research such as of public sector in China (Miao et al., 2013) or small / medium sized companies (SMCs) in Vietnam (Hai, 2012), in which training is placed less importance than personnel matters. As Japanese companies seemingly have different cultures from public sector or local SMCs, provision of training is considered to be effective to enhance OC. This leads us to the following hypothesis:

Hypothesis 6: Training is positively related to OC.

\subsubsection{Role Clarity}

Role clarity is defined as the extent to which an employee knows what is expected of him/her for adequate performance of his tasks and job responsibilities (Rizzo, House, \& Lirtzman, 1970). Role clarity would enhance a sense of felt responsibility and as such would bring about an increase in OC among employees (Gregersen \& Black, 1996). Empirical work typically finds a strong relationship between role clarity and OC in the West (Mathieu \& Zajac, 1990), in China (Newman \& Sheikh, 2012; Miao et al., 2013), in Japanese expatriates (Gregersen \& Black, 1996), in foreign employees of an American multinational company (Palich, Hom, \& Griffeth, 1995), etc.

Furthermore, it is said that there are cultural features of 'high power distance', 'uncertainty avoidance' and 'high context' in Thailand (Hall, 1976; Hofstede, 1980). In the culture of high power distance, as the power is centralized and most decisions come from the leaders and managers, "employees are expected to be told what to do" (Hofstede, 1991) but not to go beyond one's duty. In the past research, it was found that, influenced by the high power distance culture of the country, Thai employees were familiar with a tradition of top-down management; therefore, Thai employees felt uncomfortable in a participative work environment (Komin, 1990; Kumbanaruk, 1987; Rohitratana,1998).

On the other hand, in the culture of high uncertainty avoidance, organizations are expected to reduce internal uncertainty by setting rules and regulations (Hofstede, 1980, p.185). Besides, in the culture of high context, people make greater distinctions between insiders and outsiders than in the low-context culture (Hall, 1976, p.98) because their meaning is implicit in the communication among intimate members. So, it is reasonable to assume that role clarity is important for engendering OC even in Thai setting. Actually, in empirical research in Thai setting, formal rules and regulations and standard operating procedures are positively related to OC (Colignon, et al., 2007). This leads us to the following hypothesis:

Hypothesis 7: Role clarity is positively related to OC.

\subsection{Comparative Importance of Rewards}

It is assumed that Thai employees have both characteristics of individualistic and collectivistic cultures as is discussed above. Accordingly, the researcher expects that intrinsic, extrinsic and social rewards are associated with OC in Japanese companies in Thailand. However, it is expected at the same time that intrinsic rewards are more associated with OC than other rewards because Thai employees are often said to be individualistic 
according to many Japanese managers who observe their way of working closely and because they are considered to become more individualistic than before as the result of rapid industrialization. Actually, Vietnamese, who are also known collectivistic according to Hofstede (1991), have recently become more individualistic as the country becomes more developed (Hoang, 2008). This leads us to the following hypothesis:

Hypothesis 8: Intrinsic rewards are more significantly related to OC than extrinsic and social rewards.

\subsection{The Level of Education and Comparative Importance of Rewards}

Antecedents of OC are considered to be different between university graduates and 'others', employees except university graduates. As university graduates are normally more modernized and westernized on the way of thinking through higher education, they may reasonably be highly acquisitive and concerned with treatments. This leads us to the following hypotheses:

Hypothesis 9: Relationship between benefit satisfaction and OC is stronger for university graduates than others.

Hypothesis 10: Relationship between fatigue and OC is stronger for university graduates than others.

On the other hand, as Thai culture is characterized by 'high power distance', 'others' who are less westernized and still considered to be more strongly affected by such a tradition may more strongly respond to supervisor support. This leads us to the following hypothesis:

Hypothesis 11: Relationship between supervisor support and OC is weaker for university graduates than others.

In many case, Thai culture is said to possess collectivistic features. However, at the same time, university graduates are considered to be individualistic through westernized higher education. On the other hand, 'others' are also sometimes said to be individualistic as they are brought up in individualistic villages which do not boost wider human relations. So, it is accordingly expected that both parties share collectivistic and individualistic features and require human relations, autonomous working conditions and training to the same degree. This leads us to the following hypotheses:

Hypothesis 12: There is no difference on relationship between co-worker support and OC between university graduates and others.

Hypothesis 13: There is no difference on relationship between autonomy and OC between university graduates and others.

Hypothesis 14: There is no difference on relationship between training and OC between university graduates and others.

However, different approach may be required for considering the difference of association between role clarity and $\mathrm{OC}$ by educational backgrounds. As is described, the reason why role clarity is expected to be important for OC enhancement in this study is because of Thai culture such as 'high power distance', 'uncertainty avoidance' and 'high context'. These features are assumed to become weaker as people experience westernized education more. This leads us to the following hypothesis:

Hypothesis 15: Relationship between role clarity and $\mathrm{OC}$ is weaker for university graduates than others.

\section{Methods}

\subsection{Participants}

We sent questionnaires to employees in 13 Japanese manufacturing companies in Thailand. We purposely selected Japanese companies in Thailand instead of other kinds, such as state-owned or other private companies as they have a different set of HRM practices and many organizational variables would not be eligible for legitimate comparison with Japanese counterparts (Warner, 2004). 11,000 questionnaires were distributed via the HR department of participant companies. The participation was basically compulsory. With a promise to present the summary results, the HR department of each firm administered the questionnaires by distributing and collecting completed questionnaires. Each respondent was requested to put the completed questionnaire into an envelope that the researcher provided along with the questionnaire and seal it for him/her self to guarantee complete anonymity. Overall, 9,912 surveys were collected, reflecting a response rate of $90.1 \%$. We eliminated 3,001 surveys due to missing values or inappropriate characteristics such as contract workers, Japanese expatriates, etc. Consequently, the final samples comprised 6,911 Thai participants. They are extracted from 6 prefectures: Pathumthani (5), Samutprakarn (4), Sathorn (1), Ayutthaya (1), Chachoengsao (1) and Rayong (1) (the figures in parentheses are the number of companies). Other demographic information of the participants is shown in tables of appendix. We controlled for all the demographic variables in order to attenuate any concern about sample compatibility. 


\subsection{Measures}

Most questions used at this research are developed by IEWRI (1996) and later adopted by Kokubun (2006). IEWRI, International Economy and Work Research Institute, is a research institute which is located in Osaka and conducts employee opinion surveys for members of trade unions of more than 300 representative Japanese companies and give them practical advises to activate their organizations and enhance corporate productivity based on the survey results and the theory of social psychology with academic supports from university professors and researchers (http://www.iewri.or.jp/). The main reason why the researcher uses IEWRI's questions is because this research is also designed and initiated to provide meaningful advices on how to enhance the commitment or motivation of local employees to the management of Japanese companies located in foreign countries. Secondary reason is that IEWRI has rich opinion database of Japanese employees who work for Japanese companies obtained by similar way of this research, which is considered to be used for international comparison in future. The original questionnaire was developed in English and then translated into Thai language. To ensure the accuracy of the translation, the questionnaire was then translated back.

\subsubsection{Benefit Satisfaction}

Benefit satisfaction was measured on a five-item scale developed by IEWRI (1996). The items were measured on a five-point scale that ranged from 1 (dissatisfied) to 5 (satisfied). The alpha reliability was 0.805 for university graduates and 0.792 for others.

\subsubsection{Fatigue}

Fatigue was measured on a three-item scale developed by IEWRI (1996). The items were measured on a five-point scale that ranged from 1 (incorrect) to 5 (correct). The alpha reliability was 0.758 for university graduates and 0.784 for others.

\subsubsection{Supervisor Support}

Supervisor support was measured on a four-item scale originally developed by Eisenberger, et al. (1986), with minor amendment. The items were measured on a five-point scale ranged from 1 (I don't think so) to 5 (I think so). The alpha reliability was 0.813 for university graduates and 0.832 for others.

\subsubsection{Co-worker Support}

Co-worker support was measured on a four-item scale originally developed by Eisenbergeret al. (1986), with minor amendment. The items were measured on a five-point scale ranged from 1 (dissatisfied) to 5 (satisfied). The alpha reliability was 0.861 for university graduates and 0.828 for others.

\subsubsection{Autonomy}

Autonomy was measured on a four-item scale developed by IEWRI (1996). The items were measured on a four-point scale that ranged from 1 (I don't feel so) to 5 (I feel so). The alpha reliability was 0.761 for university graduates and 0.788 for others.

\subsubsection{Training Provision}

Training provision was measured on a three-item scale developed by IEWRI (1996). The items were measured on a five-point scale that ranged from 1 (I don't think so) to 5 (I think so). The alpha reliability was 0.800 for university graduates and 0.763 for others.

\subsubsection{Role Clarity}

Role clarity was measured on a two-item scale developed by IEWRI (1996). The items were measured on a five-point scale that ranged from 1 (I don't think so) to 5 (I think so). The alpha reliability was 0.668 for university graduates and 0.773 for others.

\subsubsection{Organizational Commitment}

Six items were used to measure OC. Four items was adopted from IEWRI (1996) to which two additional items 'I have strong will to work hard in this company' and 'I am willing to contribute to development of this company' were added. The items were measured on a six-point scale that ranged from 1 (I don't think so) to 5 (I think so). The alpha reliability was 0.838 for university graduates and 0.841 for others.

\subsubsection{Control Variables}

Several demographic variables were included to control for individual differences. Answered figures without any conversion were used for age and organizational tenure. Sample dummy shows university graduates or others. Gender, turnover experience, marital status, indirect/direct department, managerial/non-managerial position were 
also measured. Twelve dummy variables were created to control for the thirteen different companies.

\section{Results}

\subsection{Analysis}

We conducted an exploratory factor analysis of all items (except control variables) to examine measurement invariance between university graduates and others. The results of the factor analysis with varimax rotation are presented in Table 1, confirming an eight-factor solution for all the items of benefit satisfaction, fatigue, supervisor support, co-worker support, autonomy, training provision, role clarity and OC. The factor structure was the same for university graduates and others; therefore, we are convinced that both university graduates and others ascribed the same meanings to the scale items used in the current study (Milfont \& Fischer, 2010).

Descriptive statistics for both university graduates and others are presented in Table 2 . We tested our hypotheses using hierarchical regression analysis. We entered the control variables in Step 1 and main effects of benefit satisfaction, fatigue, supervisor support, co-workers support, autonomy, role clarity and training in Step 5. In Step 6, we entered sample variable ( 1 for university graduates and 0 for others), its interaction terms with main effects for the entire sample to test university graduates moderation. Variables forming the interaction term were entered to minimize multicollinearity among the interaction terms and their components (Akien \& West, 1991). In Step 2 to 4, main effects were separately entered by the kind of rewards (extrinsic, social and intrinsic rewards) to test their comparative importance. In addition, we conducted separate regression analysis using university graduates and others. All regression results are presented in Table 3.

Step 1 presents the results when only the control variables are included in the regression to predict OC. Four out of seven demographic variables were found to influence OC. Among them, age and marital status was positively and tenure and indirect department were negatively related to OC. That means that employees of aged, newcomer, married and direct department tend to have higher OC than those of younger, veteran, single and indirect department.

Step 2 presents the results when two variables of extrinsic rewards are added to the regression. Likewise, Step 3 and 4 present the results when two variables of social rewards and three variables of intrinsic rewards are respectively added to the regression. All the seven reward variables were significantly associated with OC. Observing adjusted $\mathrm{R}^{2}$, extrinsic, social and intrinsic rewards explained $21 \%, 21 \%, 32 \%$ of additional variance in OC, respectively. This implies that all of three types of reward are important for OC, although intrinsic rewards are more important than other two rewards supporting for Hypotheses 8.

Step 5 presents the results when all the seven reward variables are added to the regression. Fatigue is negatively and the other six reward variables are positively associated to the regression significantly $(p<0.01)$. This model provides support for Hypotheses 1-7.

At step 6, the relationship between benefit satisfaction and OC was moderated by the sample, showing that their relationship was stronger for university graduates than others $(\beta=0.20, p<0.01)$. Likewise, the relationship between fatigue and $\mathrm{OC}$ was moderated by the sample, too $(\beta=-0.08, \mathrm{p}<0.01)$. In other words, university graduates' OC was affected more by benefit satisfaction and fatigue compared with others. However, on the other hand, the relationships of supervisor support with $\mathrm{OC}$ and the relationship of role clarity with OC were weaker for university graduates than others, respectively $(\beta=-0.13, \mathrm{p}<0.01 ; \beta=-0.09, \mathrm{p}<0.05)$, which suggests that supervisor support and clear role are less important in forming OC for university graduates than others. The significant results of these moderation tests are consistent with Hypothesis 9, 10, 11 and 15. The relationships of other variables with OC showed no significant difference between university graduates and others, supporting Hypothesis 12, 13 and 14.

\subsection{Discussion}

The objective of the present study was to investigate the antecedents of the organizational commitment (OC) of employees working in the Japanese companies in Thailand. Our findings demonstrate that extrinsic rewards, social rewards and intrinsic rewards engendered higher levels of $\mathrm{OC}$, although the magnitude is stronger for intrinsic rewards than others. The point that intrinsic rewards have larger influence on OC than social and extrinsic rewards is similar to the findings of previous work conducted on samples from Western organizations, which highlight intrinsic factor as the main influence on OC (Goulet \& Frank, 2002; Steijn \& Leisink, 2006), and different from the findings from the research in China, which highlight extrinsic and social factors as the main influence (Chiu, Luk, \& Tang, 2002; Newman \& Sheikh, 2012; Miaoet al., 2013).

A considerable reason why Thai employees show more similar result to those in the West than in China in comparative magnitude of three rewards may be that Thai people have more individualistic culture which is 
originated from isolated structure of villages they are brought up or attributed to Hinayana Buddhism and rich natural resources (Tanno, 1991; Wilson, 1962). In addition, rapid economic development for the last several decades may also have engendered such more individualistic culture than it was before in Thailand.

However, at the same time, we easily notice from more precise observations that Thailand still has faces as a developing country. In line with Hypotheses 1 and 2, extrinsic rewards were found to influence organizational commitment to a high degree of significance. This contradicts findings from some of previous studies in the West, which suggest the extrinsic benefits have limited impact on the commitment of employees (Goulet \& Frank, 2002; Steijn \& Leisink, 2006), but is supportive of findings from work on Asian organizations (Chiu, Luk, \& Tang, 2002; Miao, et al., 2013; Newman \& Sheikh, 2012). This finding might be attributed to the fact that our work was done in the context of a transitional economy in which there is a lower standard of living than in the West and individuals are therefore more responsive to financial or physical rewards. In addition, relatively substantial fringe benefits packages provided to employees working for Japanese companies may be a major incentive in the light of increase in the cost of living witnessed in recent years.

In line with Hypotheses 3 and 4, supervisor and co-worker supports were found to have a significant influence on OC. These findings provide further evidence of the importance of social rewards in a collectivistic society such as Thailand. This result may be at the same time preferable observation for Japanese companies which intend to transplant activities in Thailand as they are also known collectivistic and members are requested to build strong relationships with their supervisors and co-workers in a workplace characterized by respect for seniority and high levels of reciprocity between individuals.

Autonomy was found to influence OC, providing support for Hypotheses 5. This is in line with findings from previous empirical work on organization in the West (Steijn \& Leisink, 2006) and China (Chen \& Aryee, 2007; Miao, et al., 2013), and suggests that Thai employees tend to be more committed if they are provided with discretion on the work. Being provided with autonomy should provide a signal to employees that they are trusted and valued by their organization, and in turn engender higher levels of OC.

However, at the same time, it must be taken note that this result could also be consistent with the Thai people's characteristics that they are individualistic, reluctant to be controlled from others, low loyalty, low sense of belonging, willing to become independent, dislike following the rules, etc, making the corporate management difficult in Thailand (Tanno, 1991). As Japanese expatriate managers notice these blemishes of Thai employees, they dominate information, decision-making, status and financial resources, without providing full discretion to Thai staffs and accordingly, many Japanese companies have continued huge reliance on expatriate managers. At the same time, the reason of such circumstance is often said to be that Japanese managers have a negative image toward skills or abilities of local employees, which prohibits them from recruiting highly qualified local employees (Nihon Keizai Dantai Rengokai, 2006). In this sense, the most significant problems for Japanese companies might be not only the inability of Thai employees to work cooperatively but also the inability of Japanese managers to completely trust local employees (Colignon et al., 2007).

Role clarity was also found to influence OC, providing support for Hypotheses 7. This is in line with findings from previous empirical work (Mathieu \& Zajac, 1990; Newman \& Sheikh, 2012; Miaoet al., 2013), and suggests that Thai employees tend to be more committed if they are provided with high role clarity on the work. Role clarity would enhance a sense of felt responsibility and as such would bring about an increase in OC among employees (Gregersen \& Black, 1996).

Likewise, the finding that the provision of training enhances OC, providing support for Hypotheses 6, is in line with most other findings from empirical work in Asia. However, it contradicts the findings of some previous work conducted on samples in the West, which find that training does little to enhance OC. This difference may be perhaps attributed to generally low income level of Thailand, where people cannot spend for skill improvement fully except they are members of stable and big companies which spend for them. In such a circumstance, a company's training provision will be certainly perceived as a reward and in turn cause increase of OC.

However, the significant interaction result as per Hypotheses 9 and 10 suggest that the relationships of OC with benefit satisfaction and fatigue are greater among university graduates compared with others. On the other hand, insignificant interaction results as per Hypotheses 12,13 and 14 suggest that there is no significant difference between university graduates and others on the relationships of OC with co-worker support, autonomy and training. Besides, the result of significant but adverse interaction as per Hypotheses 11 and 15 suggests that the relationship of OC with supervisor support and role clarity is weaker among university graduates compared with others. 

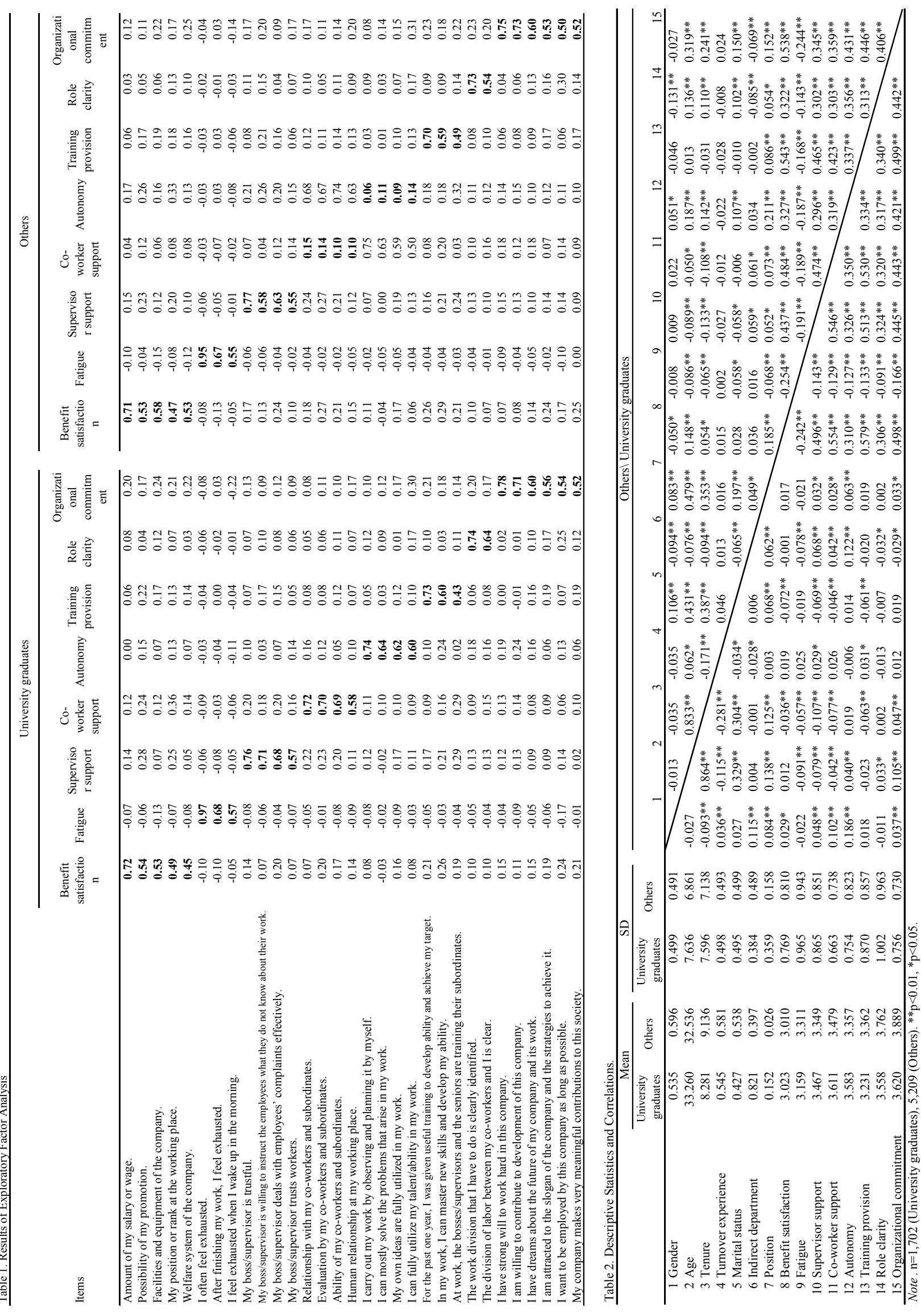
Table 3. Results of Hierarchical Analyses.

Organizational commitment

(University graduates and Others, $\mathrm{n}=6,911$ )

\begin{tabular}{|c|c|c|c|c|c|c|c|c|c|c|c|c|}
\hline \multirow{2}{*}{$\begin{array}{l}\text { Variables } \\
\text { Gender }\end{array}$} & \multicolumn{2}{|c|}{ Step 1} & \multicolumn{2}{|c|}{ Step 2} & \multicolumn{2}{|c|}{ Step 3} & \multicolumn{2}{|c|}{ Step 4} & \multicolumn{2}{|c|}{ Step 5} & \multicolumn{2}{|c|}{ Step 6} \\
\hline & -0.01 & & 0.00 & & -0.03 & $* *$ & -0.02 & * & -0.02 & $*$ & -0.04 & $* *$ \\
\hline Age & 0.21 & $* *$ & 0.13 & $* *$ & 0.19 & $* *$ & 0.15 & $* *$ & 0.12 & $* *$ & 0.16 & $* *$ \\
\hline Tenure & -0.09 & $* *$ & -0.01 & & -0.01 & & -0.04 & & 0.00 & & -0.04 & $*$ \\
\hline Turnover experience & 0.00 & & 0.01 & & 0.01 & & 0.01 & & 0.02 & $*$ & 0.01 & \\
\hline Marital status & 0.03 & $* *$ & 0.05 & $* *$ & 0.04 & $* *$ & 0.03 & $* *$ & 0.04 & $* *$ & 0.03 & ** \\
\hline Indirect department & -0.09 & $* *$ & -0.09 & $* *$ & -0.12 & $* *$ & -0.08 & $* *$ & -0.10 & $* *$ & -0.06 & $* *$ \\
\hline Position & 0.00 & & -0.04 & $* *$ & -0.03 & $* *$ & -0.03 & $* *$ & -0.05 & $* *$ & -0.03 & $* *$ \\
\hline Company 1 (dummy) & -0.15 & $* *$ & -0.10 & $* *$ & -0.14 & $* *$ & -0.13 & $* *$ & -0.12 & $* *$ & -0.09 & $* *$ \\
\hline Company 2 (dummy) & -0.02 & & -0.01 & & -0.04 & $*$ & -0.04 & $* *$ & -0.04 & $* *$ & -0.03 & $*$ \\
\hline Company 3 (dummy) & -0.04 & $* *$ & -0.01 & & -0.02 & & -0.03 & $* *$ & -0.02 & & -0.03 & $* *$ \\
\hline Company 4 (dummy) & -0.07 & $* *$ & -0.04 & $* *$ & -0.06 & $* *$ & -0.05 & $* *$ & -0.04 & $* *$ & -0.04 & $* *$ \\
\hline Company 5 (dummy) & 0.02 & & 0.05 & $* *$ & 0.02 & & 0.04 & $* *$ & 0.04 & $* *$ & 0.04 & $* *$ \\
\hline Company 6 (dummy) & -0.18 & $* *$ & -0.09 & $* *$ & -0.16 & $* *$ & -0.12 & $* *$ & -0.09 & $* *$ & -0.09 & $* *$ \\
\hline Company 7 (dummy) & -0.03 & $*$ & -0.02 & * & -0.03 & $* *$ & -0.03 & $* *$ & -0.03 & $* *$ & -0.03 & $* *$ \\
\hline Company 8 (dummy) & -0.05 & $* *$ & -0.05 & $* *$ & -0.06 & $* *$ & -0.04 & $* *$ & -0.04 & $* *$ & -0.04 & $* *$ \\
\hline Company 9 (dummy) & 0.00 & & 0.02 & & 0.02 & & 0.01 & & 0.02 & & 0.03 & \\
\hline Company 10 (dummy) & 0.05 & $* *$ & -0.01 & & 0.01 & & 0.00 & & -0.02 & & -0.01 & \\
\hline Company 11 (dummy) & -0.01 & & -0.01 & & -0.01 & & -0.01 & & -0.01 & & 0.00 & \\
\hline Company 12 (dummy) & -0.02 & & -0.02 & & -0.04 & $* *$ & -0.04 & $* *$ & -0.04 & $* *$ & -0.04 & $* *$ \\
\hline \multicolumn{13}{|l|}{ Extrinsic rewards } \\
\hline Benefit satisfaction & & & 0.46 & $* *$ & & & & & 0.17 & $* *$ & 0.14 & $* *$ \\
\hline Fatigue & & & -0.06 & $* *$ & & & & & -0.04 & $* *$ & -0.03 & $* *$ \\
\hline \multicolumn{13}{|l|}{ Social rewards } \\
\hline Supervisor support & & & & & 0.28 & $* *$ & & & 0.10 & $* *$ & 0.12 & $* *$ \\
\hline Co-worker support & & & & & 0.26 & $* *$ & & & 0.06 & $* *$ & 0.07 & $* *$ \\
\hline \multicolumn{13}{|l|}{ Intrinsic rewards } \\
\hline Autonomy & & & & & & & 0.23 & $* *$ & 0.18 & $* *$ & 0.18 & $* *$ \\
\hline Training provision & & & & & & & 0.31 & $* *$ & 0.16 & $* *$ & 0.15 & $* *$ \\
\hline Role clarity & & & & & & & 0.24 & $* *$ & 0.20 & $* *$ & 0.20 & $* *$ \\
\hline Sample & & & & & & & & & & & -0.01 & \\
\hline Sample $\times$ Benefit Satisfaction & & & & & & & & & & & 0.20 & ** \\
\hline Sample $\times$ Fatigue & & & & & & & & & & & -0.08 & $* *$ \\
\hline Sample $\times$ Supervisor support & & & & & & & & & & & -0.13 & $* *$ \\
\hline Sample $\times$ Co-worker support & & & & & & & & & & & -0.06 & \\
\hline Sample $\times$ Autonomy & & & & & & & & & & & 0.07 & \\
\hline Sample $\times$ Training provision & & & & & & & & & & & -0.03 & \\
\hline Sample $\times$ Role clarity & & & & & & & & & & & -0.09 & $*$ \\
\hline $\mathrm{R}^{2}$ & 0.10 & & 0.31 & & 0.31 & & 0.42 & & 0.46 & & 0.48 & \\
\hline Adjusted $\mathrm{R}^{2}$ & 0.10 & & 0.30 & & 0.31 & & 0.42 & & 0.46 & & 0.48 & \\
\hline $\mathrm{F}$ & 39.31 & $* *$ & 143.99 & $* *$ & 149.68 & $* *$ & 226.43 & $* *$ & 229.72 & $* *$ & 185.77 & $* *$ \\
\hline
\end{tabular}

Note. ${ }^{*}$ Significance at the $5 \%$ level; $* *$ Significance at the $1 \%$ level. 


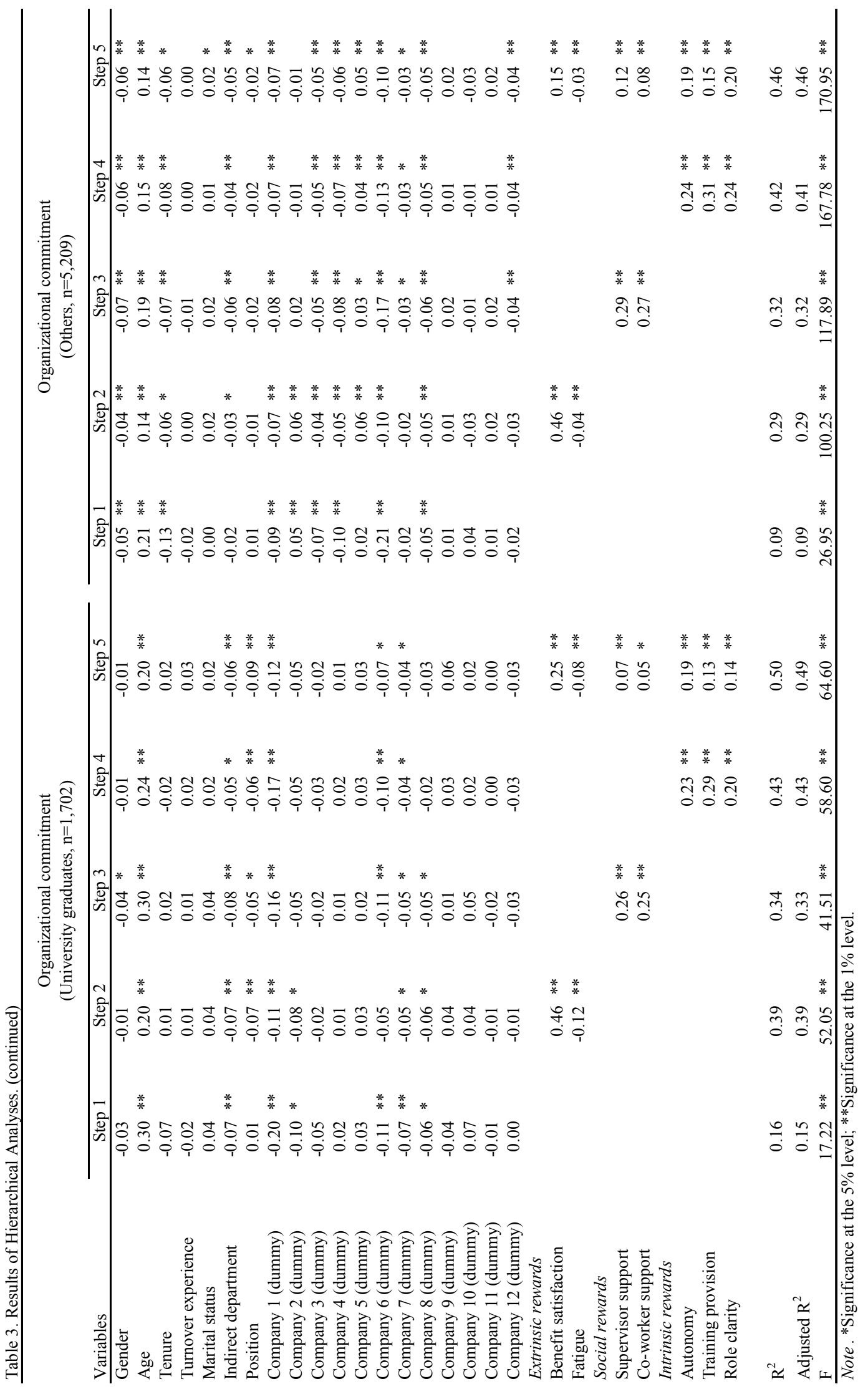




\section{Implications for Theory and Practice}

The present study contributes to the literature in four main ways. First, in line with previous work, it shows that national culture is an important factor to determine antecedents of organizational commitment (OC) (Glazer, Daniel, \& Short, 2004). Specifically, it highlights differences between the factors that enhance the OC of employees working in Thailand and employees working in the West. Compared to employees from less hierarchical, more individualistic cultures in the West, employees working in Thailand, which are of more collectivistic cultures, typically respond more positively to the existence of social rewards, namely high-quality relationships with others in the workplace.

Second, however, it became also apparent that the East is not an area of single culture. OC of Thai employees in this research is more associated with intrinsic rewards than extrinsic and social rewards, whereas that of Chinese employees in previous research is more correlated with extrinsic and social rewards than intrinsic rewards. This difference would partly be because of cultural difference of Thailand from China and other Asian countries. Some previous research shows that Thailand has dual faces of collectivistic and individualistic society due to its isolated family structures in the village, Hinayana Buddhism and rich natural resources (Tanno, 1991; Wilson, 1962). Anyway, for corporate managers who are inclined to rely on monetary rewards and social activities for motivating employees and do not fully consider of the employees' way of working and self-development opportunity, this result will be much important to be referred to change their way of management in Thailand to better direction.

Third, whereas provision of training has been shown to be less important in the West in some previous research, the results of this study demonstrate that in Thailand it is important, as were similarly shown in other developing countries (Owoyemi, Oyelere, \& Elegbede, 2011; Newman, et al., 2011). The reason why the results obtained in Thailand is different from the one in the West might be because employees in Thailand are still technically immature in general and do not cause mismatch between the training a company provides and the skill an employee wants to obtain. As most employees in Thailand do not possess enough remedy to enhance their own skill, most kind of training offered by a company may be perceived as enough reward for them to reciprocate to the company. The fact that most results obtained in other studies conducted in setting of transitional economies find positive and significant relations between training and OC supports this assertion. Although not a few companies tend to reduce expenditure for training due to high turnover rate and recent economic downturn in Thailand, it will be important to maintain the volume or quality of training for keeping OC of employees in good condition.

Forth, some differences between university graduates and others became clear. Namely, benefit satisfaction and fatigue control are more important for engendering OC of university graduates than of others whereas supervisor support and role clarity are more important for enhancing $\mathrm{OC}$ of others than of university graduates. However, other rewards, supports from co-workers, autonomy and training, show no significant difference between university graduates and others on association with OC. Among them, the result of higher association of benefit satisfaction and fatigue with OC for university graduates than others could be interpreted that university graduates are more acquisitive and demanding good payment, position, work-life balance, etc. than others. This result might be supportive to companies which can afford to take care of employees' welfares and fulfill their demand on material things. On the other hand, the lower association of supervisor support and role clarity with OC for university graduates would imply some features of Thai culture such as power distance and high context are weaker for university graduates than others, which may be due to viewpoint widening through higher and more westernized education, making empowerment and participatory management easier. Other results that supports from co-workers, autonomy and training are related with $\mathrm{OC}$ to the same degree for university graduates and others would be interpreted that in Thailand university graduates who cultivate more westernized view than others and others who have more isolated village sprit than university graduates share collectivistic / individualistic culture to the same degree.

\section{Study Limitations and Suggestions for Future Research}

There are two significant limitations on this research. The first one is of features specific to countries. This research aimed to clarify relationship between OC and various rewards of employees working for Japanese companies in Thailand. However, the results need to be tested further as it is ambiguous whether they are unique to Japanese companies in Thailand or common to those of different origins or in different countries. If there is any difference, different advices have to be done to the management of companies according to where they are from or where they locate. By doing the same survey in other nations, this problem will be solved in future research. 
The second limitation of this research is about reliability. This study used self-report data from single respondents, which may have resulted in common method bias. Future research might consider the inclusion of supervisor-rated scales to reduce common method bias and remedy the weakness of the present study design.

\section{References}

Aiken, L. S., \& West, S. G.. (1991). Multiple regression: Testing and interpreting interactions. Thousand Oaks, CA: Sage.

Amornpipat, I., McLean, G. N., \& Katekaew, M. (2014). Leadership and organizational commitment: The case of a Thai private university. 2014 Iratrachar Amornpipat, Gary N. McLean, and Meta Katekaew. http://airline.kbu.ac.th/old/download/download/research/research02.pdf

Azeem S.M. (2010). Personality hardiness, job involvement and job burnout among teachers. International Journal of Vocational and Technical Education, 2(3), 36-40.

Barrett, A., \& O'Connell, P. J. (2001). Does training generally work? The returns to in-company training. Industrial \& Labor Relations Review, 54(3), 647-662. https://doi.org/10.2307/2695995

Bartlett, K. R. (2001). The relationship between training and organizational commitment: A study in the health care field. Human Resource Development Quarterly, 12(4), 335-352. https://doi.org/10.1002/hrdq.1001

Becker, G.S. (1993). Human capital: A theoretical and empirical analysis with special reference to education (3rd ed.). Chicago, IL: University of Chicago Press.

Beukhof, G., De Jong, M. J., \& Nijhof, W. J. (1998). Employee commitment in changing organization: An exploration. Journal of European Industrial Training, 22(6), 243-248. https://doi.org/10.1108/03090599810224701

Boyacigiller, N., \& Adler, N. J. (1991). The parochial dinosaur: Organizational suicide in global context.Academy of Management Review, 16, 262-290. https://doi.org/10.5465/AMR.1991.4278936

Burke, R.J. (1995). Benefits of formal training courses within a professional services firm. The Journal of Management Development, 14(3), 3-13. https://doi.org/10.1108/02621719510078920

Chen, Z. X., \& Aryee, S. (2007). Delegation and employee work outcomes: An examination of the cultural context of mediating processes in China. Academy of Management Journal, 50, 226-238. https://doi.org/10.5465/AMJ.2007.24162389

Chiaburu, D. S., \& Harrison, D. A. (2008). Do coworkers make the place? Conceptual synthesis and meta-analysis of lateral social influences in organizations. Journal of Applied Psychology, 93(5), 1082-1103. https://doi.org/10.1037/0021-9010.93.5.1082

Chiu, R. K., Luk, V. W. M., \& Tang, T. L. P. (2002). Retaining and motivating employees: Comparison preferences in Hong Kong and China. Personnel Review, 31, 402-431.https://doi.org/10.1108/00483480210430346

Colignon, R. A., Usui, C., Kerbo, H., \& Slagter, R. (2007). Employee commitment in US and Japanese firms in Thailand. Asian Social Science, 3(11), 16-32. Retrieved from http://digitalcommons.calpoly.edu/cgi/viewcontent.cgi?article=1051\&context=ssci_fac

Chongvisal, R. (2002). Effects of middle supervisor's emotional intelligence, the 5-factor model of personality, and model of full-range of leadership on job performance and subordinate'sjob satisfaction in business organization. Journal of Public Administration, 3, 77-111. (in Thai).

Eby, L. T., Freeman, D. M., Rush, M. C., \& Lance, C. E. (1999). Motivational bases of affective organizational commitment: A partial test of an integrative theoretical model. Journal of Occupational and Organizational Psychology, 72(4), 463-483. https://doi.org/10.1348/096317999166798

Employers Confederation of Thailand. (2012). Wakateyunojinzai no kakutoku, ikusei, kakuho: Asia syokoku no hikakutenbo to globalization jidaini okeru senryakuteki HRM/HRD no hitsuyosei (Acquisition, development and securing of young and talented human resources: Comparative perspectives in Asian countries and necessity of strategic HRM/HRD in the era of globalization). (Japanese). Retrieved from http://www.hidajapan.or.jp/jp/project/eocp/info/

Eisenberger, R., Huntington, R., Hutchison, S., \& Sowa, D. (1986). Perceived organizational support. Journal of Applied Psychology, 71, 500-507. https://doi.org/10.1037/0021-9010.71.3.500

Froese, F.J., \& Xiao, S. (2012). Work Values, Job Satisfaction and Organizational Commitment in China. The 
International Journal of Human Resource Management, 23(10), 2144-2162. https://doi.org/10.1080/09585192.2011.610342

Gautam, T., van Dick, R., \& Wagner, U. (2001). Organizational commitment in Nepalese settings. Asian Journal of Social Psychology, 4(3), 239-248.https://doi.org/10.1111/1467-839X.00088

Glazer, S., Daniel, S. C., \& Short, K. M. (2004). A study of the relationship between organizational commitment and human values in four countries. Human Relations, 57(3), 323-345. https://doi.org/10.1177/0018726704043271

Goulet, L. R., \& Frank, M. L. (2002). Organizational commitment across three sectors: Public, non-profit, and for-profit. Public Personnel Management, 31(2), 201-210. https://doi.org/10.1177/009102600203100206

Gregersen, H. B., \& Black, J. S. (1996). Multiple commitments upon repatriation: The Japanese experience. Journal of Management, 22(2), 209-229. https://doi.org/10.1177/014920639602200202

Haar, J. M., \& Spell, C. S. (2004). Programme knowledge and value of work-family practices and organizational commitment. International Journal of Human Resource Management, 15(6), 1040-1054. https://doi.org/10.1080/09585190410001677304

Haghirian, P. (2010). Innovation and Change in Japanese Management. Springer.

Hagiwara, M. (2014). Thai niokeru genchi jinzai no saiyo to teicyaku: Nikkei kigyo 6 sha eno interview chosa kara (Recruitment and retention of local staffs in Thailand: From interview survey to 6 Japanese Companies). Works Report 2014. Recruit Works Institute. (Japanese). http://www.works-i.com/pdf/140707_tgj.pdf

Hai, H.T. (2012). Factors influencing organizational commitment and intention to stay of core employees in small-medium sized companies in Ho Chi Minh City. University of Economics Ho Chi Minh City, International School of Business, Ho Chi Minh City.

Hall, E.T. (1976). Beyond Culture. New York.

He, Y., Lai, K. K., \& Lu, Y. (2011). Linking organizational support to employee commitment: Evidence from hotel industry of China. International Journal of Human Resource Management, 22(1), 197-217. https://doi.org/10.1080/09585192.2011.538983

Hoang, H. (2008). Culture and management: A study of Vietnamese cultural influences on management style (Unpublished doctoral dissertation). Capella University, Minnesota, United States.

Hofstede, G. (1980). Culture’s consequence, Beverly Hills, CA: Sage Publications.

Hofstede, G. (1991). Cultures and organizations. Intercultural cooperation and its importance for survival. Software of the mind.London: McIraw-Hill.

Hofstede, G. (2001). Culture's consequences (2nd ed). Beverly Hills: Sage.

Horie, M. (2016). Keizaireport: Thai keizai no genjo to kongo no tenbo (Economic report: The present condition and future perspective). Mitsubishi UFJ Research \& Consulting. (Japanese). Retrieved from http://www.murc.jp/thinktank/economy/analysis/research/report_160530.pdf

International Economy and Work Research Institute. (1996). ONION2 sankagata soshiki to shiteno rodo kumiai no saisei: Syakai shinrigaku karano teigen (ONION2: Renovation of trade union as an organization for participation and engagement). International Economy and Work Research Institute. (Japanese).

International Monetary Fund. (2016). World economic outlook databases October 2016. Retrieved fromhttp://www.imf.org/external/ns/cs.aspx?id=28

Jackson, K. \& Tomioka, M. (2004). The changing face of Japanese management, London: Routledge.

Japan External Trade Organization. (2016). Japanese trade and investment statistics. http://www.jetro.go.jp/en/reports/statistics/

Kokubun, K. (2006). Globalization and industrial reallocation: How to motivate Malaysian workers. Paper presented at the 3rd International Globalization Studies Network (GSN) Conference, Universiti Kebangsaan Malaysia.

Komin, S. (1990). Culture and work-related values in Thai organizations. International Journal of Psychology, 25(3-6), 681-704. https://doi.org/10.1080/00207599008247921

Koonmee, K., Singhapakdi, A., Virakul, B., \& Lee, D. (2010). Ethics institutionalization, quality of work life, 
and employee job-related outcomes: A survey of human resource managers in Thailand. Journal of Business Research, 63(1), 20-26. https://doi.org/10.1016/j.jbusres.2009.01.006

Korczynski, M., Shire, K., Frenkel, S., \& Tam, M. (2000). Service work in customer capitalism: Customers, control and contradictions. Work, Employment and Society, 14(4), 669-688.https://doi.org/10.1017/S0950017000000416

Kumbanaruk, T. (1987). Japanese QCC in Thailand. Paper presented at the Joint Symposium on Thai-Japanese Relations: Development and Future Prospect, Bangkok, Thailand.

Lee, R. T., \& Ashforth, B. E. (1996). A meta-analytic examination of the correlates of the three dimensions of job burnout. Journal of Applied Psychology, 81(2), 123. https://doi.org/10.1037/0021-9010.81.2.123

Limpanitgul, T., Boonchoo, P., \& Photiyarach, S. (2014). Coworker support and organizational commitment: A comparative study of Thai employees working in Thai and American airlines. Journal of Hospitality and Tourism Management, 21, 100-107. https://doi.org/10.1016/j.jhtm.2014.08.002

Loscocco, K. A. (1990). Reactions to blue-collar work: A comparison of women and men. Work and Occupations, 17(2), 152-177.https://doi.org/10.1177/0730888490017002002

Marta, J. K., Singhapakdi, A., Lee, D. J., Sirgy, M. J., Koonmee, K., \& Virakul, B. (2013). Perceptions about ethics institutionalization and quality of work life: Thai versus American marketing managers. Journal of Business Research, 66(3), 381-389. https://doi.org/10.1016/j.jbusres.2011.08.019

Malhotra, N., Budhwar, P., \& Prowse, P. (2007). Linking rewards to commitment: An empirical investigation of four UK call centres. International Journal of Human Resource Management, 18(12), 2095-2128. https://doi.org/10.1080/09585190701695267

Mathieu, J. E., \& Zajac, D. M. (1990). A review and meta-analysis of the antecedents, correlates, and consequences of organizational commitment. Psychological Bulletin, 108(2), 171. https://doi.org/10.1037/0033-2909.108.2.171

Meyer, J. P., Stanley, D. J., Herscovitch, L., \& Topolnysky, L. (2002). Affective, continuous, and normative commitment to the organization: A meta-analysis of antecedents, correlates, and consequences. Journal of Vocational Behavior, 61, 20-52. https://doi.org/10.1006/jvbe.2001.1842

Miao, Q., Newman, A., Sun, Y., \& Xu, L. (2013). What factors influence the organizational commitment of public sector employees in China? The role of extrinsic, intrinsic and social rewards. International Journal of Human Resource Management, 24(17), 3262-3280. https://doi.org/10.1080/09585192.2013.770783

Milfont, T. L., \& Fischer, R. (2010). Testing measurement invariance across groups: Applications in cross-cultural research. International Journal of Psychological Research, 3, 111-121. Retrieved from file:///C:/Users/user/Downloads/857-2261-1-PB.pdf

Morishita, M. (2012). Global jinzai management no genkai: Asia syuyo shinko 6 kakoku jinzai management chosa gaiyo, Thai/Indo (Limit of global human resource management: Human resource management survey of Asian newly industrialized major 6 countries, Thailand and India). Kikan Seisaku Keikei Kenkyu, 2, 149-159. (Japanese). Retrieved from http://www.murc.jp/thinktank/rc/journal/quarterly/201402

Mottaz, C. J. (1985). The relative importance of intrinsic and extrinsic rewards as determinants of work $\begin{array}{llll}\text { satisfaction. The } & \text { Sociological 26(3), }\end{array}$ https://doi.org/10.1111/j.1533-8525.1985.tb00233.x

Mottaz, C.J. (1988). Determinants of organizational commitment. Human Relations, 41(6), 467-482.https://doi.org/10.1177/001872678804100604

Nazir, S., Shafi, A., Qun, W., Nazir, N., \& Tran, Q. D. (2016). Influence of organizational rewards on organizational commitment and turnover intentions. Employee Relations, 38(4), 596-619. https://doi.org/10.1108/ER-12-2014-0150

Newchantuek, P. (2002). The relationship between supervisor's leadership, organizational commitment and job performance of employee of ITV public company limited (Unpublished master's thesis). Kasetsart University, Bangkok, Thailand. (in Thai).

Newman, A., \& Sheikh, A. Z. (2012). Organizational commitment in Chinese small- and medium-sized enterprises: The role of extrinsic, intrinsic and social rewards. International Journal of Human Resource Management, 23(2), 349-367.https://doi.org/10.1080/09585192.2011.561229 
Newman, A., Thanacoody, R., \& Hui, W. (2011). The impact of employee perceptions of training on organizational commitment and turnover intentions: A study of multinationals in the Chinese service sector.International Journal of Human Resource Management, 22(8), 1765-1787. https://doi.org/10.1080/09585192.2011.565667

Nilpan, D. (2000). The relationship among leadership of executive, job satisfaction and organizational commitment of employee: Case study on the telecommunication industry (Unpublished master's thesis). Kasetsart University, Bangkok, Thailand. (in Thai).

Nihon Keizai Dantai Rengokai. (2006). Nihon kigyo no chugoku niokeru white color jinzai senryaku (Employment strategies for white-collar employees of Japanese corporations in China), 16 May 2006. Retrieved from http://www.keidanren.or.jp/japanese/policy/2006/030/honbun.pdf

Nurittamont, W. (2012). The relationship among organizational commitment, self-efficacy and businesses performance: An empirical study of hotel businesses in Thailand. Journal of Academy of Business and Economics, 12(2), 99-108.

O'Reilly, C. A., \& Caldwell, D. F. (1980). Job choice: The impact of intrinsic and extrinsic factors on subsequent satisfaction and commitment. Journal of Applied Psychology, 65(5), 559-565.https://doi.org/10.1037/0021-9010.65.5.559

Owens, P. L. (2006). One more reason not to cut your training budget: The relationship between training and organizational outcomes. Public Personnel Management, 35(2), 163-171. https://doi.org/10.1177/009102600603500205

Owoyemi, O. A., Oyelere, M., \& Elegbede, T. (2011). Enhancing employees' commitment to organisation through training. International Journal of Business and Management, 6(7), 280-286.

Palich, L. E., Hom, P. W., \& Griffeth, R. W. (1995). Managing in the international context: Testing cultural generality of sources of commitment to multinational enterprises. Journal of Management, 21(4), 671-690. https://doi.org/10.1177/014920639502100405

Pornpitakpan, C. (1999). The effects of cultural adaptation on business relationships: Americans selling to Japanese and Thais. Journal of International Business Studies, 30(2), 317-337.https://doi.org/10.1057/palgrave.jibs. 8490072

Porter, L. W., \& Lawler, E. E. (1968). Managerial attitudes and performance. Homewood, IL: Dorsey Press.

Prpic, J. K., \& Kanjanapanyakom, R. (2004). The impact of cultural values and norms on higher education in Thailand. Proceedings of the HERDSA Conference, July 2004.

Recruit Works Institute. (2013). Thai column: Thai no daisotsusha wo meguru saiyo kankyo (Recruit environment of university graduates in Thailand). Basic research: Asia 9 kakoku no jinzai market (Basic research: The labor market in Asian 9 countries). (Japanese). Retrieved from https://www.works-i.com/pdf/thailand_column01.pdf

Rizzo, J. R., House, R. J., \& Lirtzman, S. I. (1970). Role conflict and ambiguity in complex organizations. Administrative Science Quarterly, 150-163. https://doi.org/10.2307/2391486

Rohitratana, K. (1998). The role of Thai values in managing information systems; a case study of implementing an MRP systems. Proceedings of the Fifth International Working Conference of IFIP WG, 9, 188-201.

Self, D. R., Holt, D. T., \& Schaninger, W. S. (2005). Work group and organizational support: A test of distinct dimensions. Journal of Occupational and Organizational Psychology, 78(1), 133-140.

Shiino, K. (2015). Jinko bonus ki de miru yubo sijo wa (Promising market in population bonus period). JETRO Censer, March 2015. (Japanese). Retrieved from https://www.jetro.go.jp/world/reports/2015/07001938.html

Shore, L. M., \& Barksdale, K. (1998). Examining degree of balance and level of obligation in the employment relationship: A social exchange approach. Journal of Organizational Behavior, 19, 731-744. https://doi.org/10.1002/(SICI)1099-1379(1998)19:1+\%3C731::AID-JOB969\%3E3.0.CO;2-P

Siengthai, S., \& Vadhanasindhu, P. (1991). Management in a Buddhist society - Thailand. In Putti, J. M. (Ed.), Management: Asian context. Singapore: McGraw-Hill.

Sims, H. P., Szilagyi, A. D., \& McKemey, D. R. (1976). Antecedents of Work Related Expectancies. Academy of Management Journal, 19(4), 547-559. https://doi.org/10.2307/255790

Smeenk, S. G. A., Eisinga, R. N., Teelken, J. C., \& Doorewaard, J. A. C. M. (2006). The effect of HRM practices 
and antecedents on organizational commitment among university employees. International Journal of Human Resource management, 17(12), 2035-2054. https://doi.org/10.1080/09585190600965449

Steijn, B., \& Leisink, P. (2006). Organizational commitment among Dutch public sector employees. International Review of Administrative $\quad$ Sciences, $\quad 72(2), \quad$ 187-201. https://doi.org/10.1177/0020852306064609

Sugita, C. (2015). Thai no jinkenhi josyo wo meguru seisaku taiou (Government policies surrounding surging personnel costs), Mizuho Research Institute. (Japanese). Retrieved from https://www.mizuho-ri.co.jp/publication/research/pdf/insight/as150213a.pdf

Takada, H. (2015). Thai keizai, 2020 nen madewa rakkan dekinai (We cannot take an optimistic view of Thai economy till 2020). Research Today, January 28, 2015, Mizuho Research Institute. (Japanese). Retrieved from https://www.mizuho-ri.co.jp/publication/research/pdf/today/rt150128.pdf

Tanno, I. (1991). Thai no kigyo keiei no kokusai hikaku: Kokusai Keiei Kenkyujo Center project houkoku (International comparison of corporate management in Thailand: Project report of International Management Research Center). Kokusai Keiei Forum, 2, 197-203. (Japanese). Retrieved from http://klibredb.lib.kanagawa-u.ac.jp/dspace/handle/10487/1530

Teikoku Data Bank. (2016). Tokubetsu kikaku: ASEAN shinsyutsu kigyo jittai chosa (Special edition: Survey of the companies in ASEAN). Retrieved from https://www.tdb.co.jp/report/watching/press/p160504.html

Thailand Board of Investment. (2014). Seven-year investment promotion strategy (2015 - 2021): Investment promotion criteria and activities. Retrieved from https://www.dfdl.com/wp-content/uploads/2014/12/dfdl_legal_brief_boi_presentation_15dec2014.pdf

Vichian, P. (2016). Structural empowerment and organizational commitment of lecturers in private international educational institutions at Thailand. Journal of Education and Practice, 7(11), 158-163. Retrieved from http://files.eric.ed.gov/fulltext/EJ1099564.pdf

Wang, Y. (2008). Emotional bonds with supervisors and co-workers: Relationship to organizational commitment in China's foreign-invested companies. International Journal of Human Resource Management, 19(5), 916-931. https://doi.org/10.1080/09585190801993901

Warner, M. (2004). Human resource management in China revised: Introduction. International Journal of Human Resource Management, 15(4-5), 617-634. https://doi.org/10.1080/0958519042000192861

Wayne, S. J., Shore, L. M., \& Liden, R. (1997). Perceived organizational support and leader-member exchange: A social exchange perspective. Academy of Management Journal, 40(1), 82-111. https://doi.org/10.2307/257021

Whitney, R. (1994). Business systems in Asia: Firms, markets and societies. London, Newbury Park, Sage Publications.

Williamson, I. O., Burnett, M. F., \& Bartol, K. M. (2009). The interactive effect of collectivism and organizational rewards on affective organizational commitment. Cross Cultural Management: An International Journal, 16, 28-43. https://doi.org/10.1108/13527600910930022

Wilson, D. A. (1962), Politics in Thailand, Ithaca: Cornell University Press.

Wright, T. A., \& Cropanzano, R. (1998). Emotional exhaustion as a predictor of job performance and voluntary turnover, Journal of Applied Psychology, 83(3), 486-493. https://doi.org/10.1037/0021-9010.83.3.486

Yamazaki, Y., \& Petchdee, S. (2015). Turnover intention, organizational commitment, and specific job satisfaction among production employees in Thailand,' Journal of Business and Management, 4(4), 22-38. https://doi.org/10.12735/jbm.v4i4p22 
Appendix. Demographic Information.

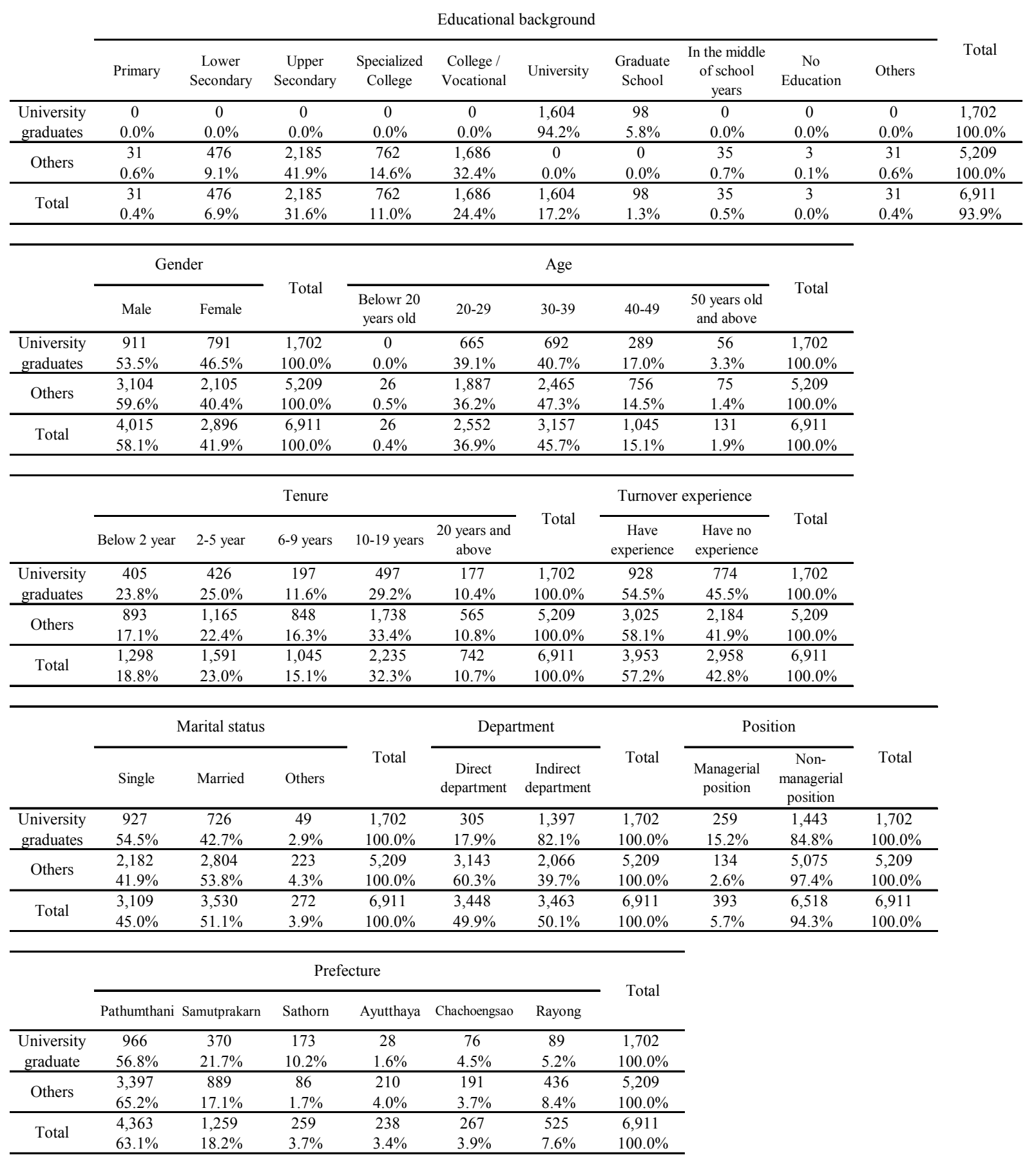

\section{Copyrights}

Copyright for this article is retained by the author(s), with first publication rights granted to the journal.

This is an open-access article distributed under the terms and conditions of the Creative Commons Attribution license (http://creativecommons.org/licenses/by/4.0/). 